\title{
RANCANG BANGUN MODEL LATIHAN KOSAKATA BAHASA INGGRIS TEKNIK BERBASIS MULTIMEDIA Yogi Widiawati ${ }^{1)}$, Sri Danaryani dan Anik Tjandra \\ Jurusan Teknik Elektro Politeknik Negeri Jakarta \\ Email:1yogiwidiawati@yahoo.com
}

\begin{abstract}
This is an extensive research based on the prior research conducted in 2010 which was called "The Frequency of Technical English Usage Used by Students of Electronics Department". This research is aimed to facilitate the students of all polytechnics in Indonesia in general, especially State Polytechnics of Jakarta, where this research was applied. The result of this research is a kind of software which is easily used and portable so that the students can use the software anywhere and anytime. It consists of 3 (three) sections of exercises. At the end of each exercise, the students are evaluated automatically by looking at the scoring system. These will encourage them to get good score by repeating it again and again. So the technical words are not problem for them. Furthermore, the students can practice technical English vocabulary both at home and in the language laboratory by using this software.
\end{abstract}

Keywords: English Technical Vocabulary, Software, portable

\section{Abstrak}

Penelitian ini dilalukan berdasarkan penelitian sebelumnya yang dilakukan pada tahun 2010 yang berjudul "Kekerapan Penggunaan Kosakata Bahasa Inggris Teknik yang digunakan Mahasiswa Jurusan Teknik Elektro". Penelitian ini dibertujuan untuk memfasilitasi mahasiswa untuk berlatih kosakata bahasa Inggris Teknik. Karena hasil penelitian ini berupa perangkat lunak maka perangkat ini dapat digunakan kapan saja dan dimana saja. Perangkat ini terdiri dari 3 bagian latihan. Dan pada akhirnya diberikan hasil evaluasi dengan sistem penilain. Hal ini akan memotivasi mahasiswa untuk belajar lebih giat lagi.

Kata Kunci: kosakata bahasa Inggris teknik, perangkat lunak, mudah dibawa

\section{PENDAHULUAN}

Mata kuliah bahasa Inggris di Politeknik Negeri Jakarta mensyaratkan mahasiswa mengetahui istilah-istilah teknik yang biasa digunakan di bengkel atau di laboratorium. Hal ini dikarenakan jika mereka lulus dan mungkin bekerja di perusahaan asing, maka ilmu yang mereka dapatkan dan pelajari akan berguna, terutama bahasa Inggris yang sesuai dengan bidang pekerjaan mereka. Tentunya mata kuliah bahasa Inggris yang berhubungan dengan bidang keteknikan (Hibah Bersaing, 2007). Dalam mempelajari bahasa Inggris ada kosakata teknik yang sering digunakan mahasiswa yang biasa mereka temui di bengkel teknik atau laboratorium teknik, dalam hal ini khususnya jurusan Teknik Elektro. Walaupun mata kuliah bahasa Inggris hanya diberikan 1 (satu) kali dalam seminggu selama 2 atau 3 jam per pertemuan, hal ini tidak mematahkan semangat dan antusiame mahasiswa mempelajari bahasa Inggris. Mereka sangat menyadari bahwa bahasa Inggris sangat penting bagi mereka pada saat mereka bekerja kelak.

Di jurusan Teknik Elektro sendiri, mata kuliah bahasa Inggris diberikan selama 4 (empat) semester dimana mata kuliah bahasa Inggris terbagi atas 2 (dua) jenis yaitu Technical English yang diberikan pada semester 3 dan 4, dan General English yang diberikan pada semester 5 
dan 6. Pembagian mata kuliah bahasa Inggris dilakukan mengingat mata kuliah ini mulai diberikan semester 3 dimana pada semester ini mahasiswa sudah banyak mengenal dan memahami benda atau eksperimen teknik, sehingga perlu diberikan bahasa Inggris teknik agar pengetahuan mereka mengenai teknik dalam bahasa Indonesia akan berjalan beriringan dengan bahasa Inggris. Pada semester 3 dan 4, mahasiswa mendapatkan pelajaran bahasa Inggris dengan tujuan khusus atau disebut dengan English for Specific Purposes (ESP). Dalam silabusnya ada topic mengenai pelajaran kosakata (English Vocabulary). Banyak kosakata yang kerap digunakan mahasiswa baik di bengkel ataupun di laboratorium (Penelitian BIL, 2010).

Berdasarkan 2 (dua) penelitian sebelumnya, maka dibutuhkan suatu model latihan yang dapat membantu mahasiswa melatih kosakata bahasa Inggris teknik yang kerap digunakan yang berhubungan dengan kegiatan bengkel dan laboratorium. Model latihan ini pun akan menjadi media yang bisa digunakan oleh setiap mahasiswa teknik, tidak hanya mahasiswa PNJ tetapi juga mahasiswa politeknik lain bahkan mahasiswa jurusan Teknik di universitas lainnya.

Kebutuhan akan model latihan ini merupakan kebutuhan primer mengingat kosakata teknik sangat penting, apalagi computer merupakan alat bantu yang sudah melekat di setiap kegiatan akademik para mahasiswa. Komputer juga merupakan alat bantu yang disediakan disetiap jurusan dan program studi, maka model ini mudah diakses. Mengingat sulitnya mendapatkan model latihan untuk bahasa Inggris teknik di took buku, maka dibutuhkan suatu usaha atau penelitian untuk membuat rancang bangun model latihan kosakata bahasa Inggris teknik. Hasil penelitian sangat berguna untuk membuka wawasan berpikir mahasiswa untuk mempelajari bidang bahasa Inggris, khususnya bidang teknik agar mereka lebih terbiasa menggunakannya. Seperti pepatah bilang: PRACTICE MAKES PERFECT.

\section{Landasan Teori}

Ada banyak cara mampelajari kosakata bahasa Inggris agar seseorang dapat mengingat dengan baik. Cara-cara tersebut antara lain adalah pengulangan (repetition), mengunakan gambar (picture dictionary), melengkapi kalimat (definition/description), dan menggunakan benda sebenarnya (using real objects). Cara-cara inilah yang sering digunakan para pengajar bahasa Inggris di Politeknik Negeri Jakarta. Juga hal ini juga bergantung pada kreativitas dan kerajinan pengajar. Karena di PNJ, khususnya jurusan Teknik Elektro, para pangajar bahasa Inggris mengalami kesulitan dalam melatih mahasiswa mempelajari dan memahami kosakata bahasa Inggris teknik. Untuk itu dibutuhkan suatu cara yang praktis dan efisien agar mahasiswa cepat mengerti dan hafal kosakata tersebut. Kebanyakan kosakata tersebut berhubungan dengan sesuatu yang digunakan di bengkel atau laboratorium (English for Engineering, 1990). Kosakata ini agak sulit karena dalam percakapan sehari-hari kosakata ini jarang dipakai atau mempunyai makna berbeda jika dilihat di kamus umum bahasa Inggris. Sebagai contoh, ada benda bengkel yang disebut dengan "bench". Dalam kamus umum bahasa Inggris seperti Oxford (Oxford Dictionary, Fourth Edition), kata ini bermakna long wooden seat placed in the public garden (yang diterjemahkan kursi taman), sementara jika dilihat makna lain di kamus bahasa Inggris teknik (English Dictionary for Engineering, 1987), kata ini bermakna work table used in the workshop or laboratory. Dengan dua makna yang berbeda ini kadang-kadang membingungkan mahasiswa.

Pada penelitian sebelumnya (Penelitian BIL, 2010), banyak ditemukan kosakata bahasa Inggris teknik yang berhubungan dengan obyek atau alat di bengkel (Describing Tools and Intruments), Proses 
Kerja alat atau mesin (Describing Objects or Process), Membaca Rumus (Reading Math and Formulae), Membaca Grafik atau Tabel (Reading Graphs and Tables), Bangun dan Sudut (Shapes and Angles), Sifat atau Karakter Bahan atau Material teknik (Properties of Engineering Materials), dan lain sbagainya.

Menurut John M. Davies (Comnmunication for Engineering Students, 1996), multimedia akan sangat membantu seseorang yang mempelajari bahasa Inggris agar dia lebih mudah memahami suatu kata dan dapat belajar lebih cepat tanpa beban. Dia menambahkan bahwa cara ini sangat membantu pengajar bahasa Inggris pula untuk mengajarkan suatu kata bahasa Inggris. Pada proses pengembangan alat bantu yang berbasis multimedia dibutuhkan beberapa software pendukung seperti (1) Visual Basic dan (2) Flash CS3. Visual basic banyak digunakan untuk membuat program software, dalam hal ini format soal-soal latihan bahasa Inggris. Sementara flash digunakan untuk membuat animasi, hiburan dan berbagai komponen web, diintegrasikan dengan video sehingga dapat menjadi aplikasi multimedia yang kaya aplikasi.

\section{METODE PENELITIAN}

Penelitian ini dilakukan di PNJ dan dilakukan selama delapan bulan dengan beberapa tahapan yaitu; (1) Tahap Perencanaan; dimana pada tahap ini dilakukan pengumpulan kosakata yang sering digunakan dan dapat dituangkan dalam model latihan, perencanaan aplikasi software dan perencanaan model latihan serta evaluasi; (2) Tahap analisis. Pada tahap ini data-data yang telah terkumpul dianalisis dan diidentifikasi dengan mendapatkan hasil modul yang sesuai dengan target. Analisis dilakukan juga terhadap pola evaluasi yang akan diterapkan; (3) Tahap Perancangan
Kegiatan. Pada tahap ini dilakukan desain pembelajaran yang sesuai dan penentuan isi materi modul latih serta tampilan; (4) Tahap Pelaksanaan Kegiatan. Pada tahap ini berupa pelkasanaan kegiatan pembuatan bahan ajar, pembuatan animasi dan uji coba modul.

\section{HASIL DAN PEMBAHASAN}

Perangkat lunak ini terdiri dari 3 (tiga) jenis latihan kosakata. Sebelum memulai, mahasiswa disuguhkan tampilan gambar judul latihan dan kemudian pada tampilan berikutnya, mahasiswa dapat menetik nama dan nomor mahasiswa untuk memulai program latihan. Latihan pertama berisi 50 (lima puluh) pertanyaan pilhan ganda dimana mahasiswa dapat menjawab dengan mengklik huruf $\mathrm{A}, \mathrm{B}, \mathrm{C}$ atau $\mathrm{D}$ untuk jawaban yang dianggap benar. Jika jawaban mahasiswa benar, maka akan mucul tanda biru dan bunyi tepuktangan, sementara kalau jawaban salah akan muncul tanda warna merah dan bunyi suara "meyesal". Suara diberikan untuk memberikan efek positip pada emosi mahasiswa dan juga untuk memberitahukan mahasiswa atau user mengenai jawaban yang telah dipilih. Selain itu, latihan ini selain untuk belajar juga untuk bermain atau fun sehingga user tidak menyadari bahwa mereka sebenarnya sedang belajar. Pada akhir setiap latihan, akan ada evaluasi atau penilaian akhir tentang berapa skor atau nilai yang diperoleh yang bersangkutan, karena akan muncul nilai akhir di tampilan. Latihan ke 2 (dua) adalah berupa gambar Cathode Ray Tube (CRT), dimana user diminta untuk melengkapi atau menamai setiap bagian dari CRT tersebut. Sistem penilaian akan sama dengan latihan yang pertama. Latihan ke 3 (tiga) atau terakhir berupa bacaan atau reading text. User diminta untuk melengkapi kosakata yang kosong di bacaan tersebut dengan kosakata yuang diberikan. Karena ini adalah modul latih kosakata maka dalam teks bacaan, ada 
beberapa kosakata yang harus dicari secara tepat untuk kalimat yang ada. Akhirnya akan ada nilai atau evaluasi yang diberikan untuk setiap jawaban yang diberikan.

Dengan modul latih ini mahasiswa tanpa sadar diajak untuk berlatih tanpa harus berpikir keras dan sulit, karena sebenarnya menghafal kosakata tidaklah sesulit yang mereka bayangkan.

\section{KESIMPULAN DAN SARAN}

Modul latih ini merupakan terobosan baru di dunia pendidikan, khususnya pendidikan untuk latihan bahasa Inggris teknik. Hal ini akan memotivasi baik pengajar bahasa Inggris maupun mahasiswa untuk berlatih secara kelompok ataupun secara individu, sehingga belajar bahasa Inggris menjadi lebih mudah dan menarik. Diharapkan software ini akan dikembangkan lagi sehingga learning English is fun.

\section{DAFTAR PUSTAKA}

Davies W. John, 1996, “Communication for Engineering Students”, London, Longman Group Limited

Hutchinson, Tom dan Allan, 1987, "English for Specific Purposes: A Learning Centred Approach”, Cambridge University Press

Trimble Louis, 1985, "English for Science and Technology”, Cambridge, Cambridge University Press

Miarso, Yusufhadi, 2004, Menyemai Benih Teknologi Pendidikan, Pustekom-Diknas, Jakarta

Sunyoto, Adi, 2010. Adobe FlashXML=Rich Multimedia Application, Andi Offset, Yogyakarta

http://www.sameshow.com/e-learningsuite.html di unduh 26 Oktober 2010 